\title{
Response
}

\section{The Association between Pulmonary Functions and Incident Diabetes: Longitudinal Analysis from the Ansung Cohort in Korea (Diabetes Metab J 2020;44: 699-710)}

\author{
Hoon Sung Choi ${ }^{1}$, Sung Woo Lee ${ }^{2}$, Jin Taek Kim², Hong Kyu Lee \\ ${ }^{1}$ Department of Internal Medicine, Kangwon National University School of Medicine, Chuncheon, \\ ${ }^{2}$ Department of Internal Medicine, Nowon Eulji Medical Center, Eulji University School of Medicine, Seoul, Korea
}

We appreciate Professor Kim's comments on our article, entitled "The association between pulmonary functions and incident diabetes: longitudinal analysis from the Ansung cohort in Korea" published in Diabetes and Metabolism Journal [1].

As you pointed out, several studies suggested that diabetes and/or hyperglycemia are associated with development of various pulmonary diseases including chronic obstructive pulmonary disease, asthma, and interstitial lung disease [2-4]. Although some cross-sectional studies have suggested that insulin resistance may contribute to decreased lung function, there have been no longitudinal studies on the effects of insulin resistance on declining lung function $[5,6]$. Therefore, at this point, there is no convincing evidence that decreased pulmonary function may be a marker reflecting the relationship between subclinical glucose intolerance status and lung dysfunction. The currently closed Ansung study conducted lung function tests only during the initial 4 years, and additional cohort studies will be needed to track the long-term relationship between lung function and insulin resistance, diabetes, and other metabolic parameters. We agree with your opinion that the link between lung function decline and other diabetes complications, including cardiovascular disease, warrants further in- vestigation.

The coronavirus disease 2019 pandemic, in which there could be many patients with asymptomatic lung disease, could be associated with potential public health problems such as diabetes, cardiovascular disease or other metabolic derangements. We appreciate your insightful opinion, and we also look forward to further epidemiologic or experimental studies on this topic.

\section{CONFLICTS OF INTEREST}

No potential conflict of interest relevant to this article was reported.

\section{REFERENCES}

1. Choi HS, Lee SW, Kim JT, Lee HK. The association between pulmonary functions and incident diabetes: longitudinal analysis from the Ansung cohort in Korea. Diabetes Metab J 2020; 44:699-710.

2. Mamillapalli C, Tentu R, Jain NK, Bhandari R. COPD and type 2 diabetes. Curr Respir Med Rev 2019;15:112-9.
Corresponding authors: Jin Taek Kim (iD https://orcid.org/0000-0001-7389-4867 Division of Endocrinology and Metabolism, Department of Internal Medicine, Nowon Eulji Medical Center, Eulji University School of Medicine, 68 Hangeulbiseong-ro, Nowon-gu, Seoul 01830, Korea

E-mail: jtkimmd@eulji.ac.kr
This is an Open Access article distributed under the terms of the Creative Commons Attribution Non-Commercial License (https://creativecommons.org/licenses/by-nc/4.0/) which permits unrestricted non-commercial use, distribution, and reproduction in any medium, provided the original work is properly cited.

\footnotetext{
Copyright $\odot 2020$ Korean Diabetes Association https://e-dmj.org
} 
3. Enomoto T, Usuki J, Azuma A, Nakagawa T, Kudoh S. Diabetes mellitus may increase risk for idiopathic pulmonary fibrosis. Chest 2003;123:2007-11.

4. Perez MK, Piedimonte G. Metabolic asthma: is there a link between obesity, diabetes, and asthma? Immunol Allergy Clin North Am 2014;34:777-84.

5. Sagun G, Gedik C, Ekiz E, Karagoz E, Takir M, Oguz A. The relation between insulin resistance and lung function: a cross sectional study. BMC Pulm Med 2015;15:139.

6. Forno E, Han YY, Muzumdar RH, Celedon JC. Insulin resistance, metabolic syndrome, and lung function in US adolescents with and without asthma. J Allergy Clin Immunol 2015; 136:304-11.e8. 